Annals of International Medical and Dental Research

E-ISSN: 2395-2822 | P-ISSN: 2395-2814

Vol-8, Issue-1 | January-February 2022

DOI: $10.53339 /$ aimdr.2022.8.1.15

Page no- 106-116 | Section- Research Article (Surgery)

\title{
An Audit on Gastrointestinal Perforation in a Tertiary Care Teaching Hospital Based in Northern Part of India: A Study of 100 Cases
}

\section{Rakesh Kumar Chanania1, Lakshay Goyal2 ${ }^{2}$ Shaina ${ }^{3}$, Sanjeev Gupta4*, Gagandeep Chanania ${ }^{5}$, Sahil Heer 6}

1Medical Officer Specialist, CHC, Kalo Majra, Patiala, Punjab, India.

Email: drrakesh1977@yahoo.co.in

Orcid ID: 0000-0002-3939-4997

2Senior resident, Department of General Surgery, Govt. Medical College And Hospital, Patiala, Punjab, India.

Email: lakshaygoya197@gmail.com

Orcid ID: 0000-0002-6375-9888

3MBBS, Govt. Medical College And

Hospital, Patiala, Punjab, India.

Email: shainagoyal0111@gmail.com

Orcid ID: 0000-0003-0844-0855

${ }^{4}$ Associate Professor, Department of General Surgery, Govt. Medical College and Hospital, Patiala, Punjab, India.

Email: drsanjivms@gmail.com

Orcid ID: 0000-0002-0627-2168

${ }^{5}$ Medical Officer Specialist, Department of E.N.T, Govt. Medical College And Hospital, Patiala, Punjab, India.

Email:drkumarigagandeepchanania@yahoo.co.in Orcid ID: 0000-0003-2635-7369

6PG student, Department of General Surgery, Govt. Medical College and Hospital, Patiala, Punjab, India.

Email: heer47@gmail.com

Orcid ID: 0000-0001-5624-5048

${ }^{*}$ Corresponding author

\section{Abstract}

Background: A prospective study was conducted on 100 patients of perforation peritonitis: To find out the incidence of gastro intestinal perforation in various age groups, sex, riral or urban, socio economic status, To find out the various causes and sites of gastra intestinal perforartions, To determine various types of procedures being done to treat gastro intestinal perforations. Methods: The study population consisted of 100 patients of perforation peritonitis admitted at surgical wards of Rajindra Hospital, Patiala. Patients underwent necessary investigations such as Blood counts, biochemical analysis and urine analysis. X-ray Abdomen and chest / USG Abdomen/Pelvis CTAbdomen (as and when required). All diagnosed patients were subjected to surgery. In all cases, operative findings and postoperative course were followed up for three months. Final outcome was evaluated on the basis of clinical, operative and radiological findings. In pre-pyloric and duodenal perforation, GRAHAM'S PATCH REPAIR carried out. In Ileal and Jejunal perforations, primary closure or exteriorization done depending upon the condition of the gut and duration of the symptoms. The patient outcome was assessed by duration of hospital stay, wound infection, wound dehiscence, leakage/entero-cutaneous fistula, intraabdominal collection/abscess, ileostomy related complications and reoperation. Wound infection was graded as per SSI grading. Results: Most common age group for perforation was 21-40 years (50\%) followed by $41-60(33 \%)$ years in present study. Mean age of the patients is $37.91+$ 13.15 years with male predominance $(78 \%)$ in our study. $4 \%$ of the patients were of upper socio-economic status while $32 \%$ of the patients were of middle and $64 \%$ of the patients were of lower socio-economic status.Abdominal pain was seen in $100 \%$ of the patients while abdominal distension was present in $69 \%$ of the patients. Nausea/Vomiting was seen in $61 \%$ of the patients while Fever and Constipation was seen in $53 \%$ and $86 \%$ of the patients respectively. Diarrhoea was seen in 3\% of the patients. Tenderness, guarding \& rigidity, distension, obliteration of liver dullness and evidence of free fluid were present in $100 \%$ of the patients. Bowel sounds were not detected in all the patients. Most common perforations were Duodena(37\%), Ileal (25\%), Gastric (25\%) followed by Appendicular $(9 \%)$, Jejunal $(4 \%)$ and Colonic perforation $(2 \%)$. The most common etiology of gastrointestinal perforations was Peptic ulcer followed by 
Annals of International Medical and Dental Research

E-ISSN: 2395-2822 | P-ISSN: 2395-2814

Vol-8, Issue-1 | January-February 2022

DOI: $10.53339 /$ aimdr.2022.8.1.15

Page no- 106-116 | Section- Research Article (Surgery)

Received: 24 September 2021

Revised: 05 November 2021

Accepted: 14 November 2021

Published: 22 December 2021
Typhoid, Appendicitis, Tuberculosis, Trauma, Malignancy and non-specific infection. In Gastric perforations, Peptic ulcer was the most common cause of perforation followed by Trauma. In Ileal perforations, Typhoid was the most common cause of perforation followed by Tuberculosis and nonspecific infection. In Appendicular perforations, most common cause was Appendicitis. In Jejunal perforations, most common cause was Trauma. In Colonic perforations, most common cause was Malignancy. Conclusions: The incidence of gastrointestinal perforations was common in 21-40 years age group followed by 41-60 years age group with male preponderance in our study. The most common site of perforations was Gastro-duodenal followed by Ileal perforations and the most common cause for these perforations was peptic ulcer followed by typhoid. The most common procedure done to treat gastrointestinal perforations was primary closure, resection and anastomosis, appendectomy and stoma formation. However, small sample size and short follow up period were the limitations of the present study.

Keywords:- Gastrointestinal Perforation.

\section{INTRODUCTION}

Gastrointestinal perforation is one of the most common cause of intra-peritoneal free air; its detection is important for diagnosis of lifethreatening conditions in patients with acute abdomen. Gastrointestinal tract perforations can occur for various causes (peptic ulcer, inflammatory disease, blunt or penetrating trauma, iatrogenic factors, infections such as typhoid, tuberculosis etc., foreign body or a neoplasm); most of these perforations are emergency conditions requiring an early recognition and a timely surgical treatment. [1]

Ileal perforation is common surgical emergency in tropical countries. It is reported to constitute the common cause of abdominal emergencies due to high incidence of enteric fever in these countries.[2] Patients with perforation peritonitis should be treated with antibiotics, i.v. fluids, electrolyte replacement and blood transfusion if required. The surgical treatment of perforation peritonitis is based on three basic principle viz. (1) to eliminate the source of bacterial contamination by treating the underlying pathologic process. (2) To decrease the degree of bacterial contamination in the peritoneal cavity. (3) To prevent recurrent or residual infection. $[3,4]$

Emergency laparotomy is performed to either repair or resect and anostomose the perforated segment or exteriorise the bowel segment bearing the perforation. An exploratory laprotomy is associated with many complication that arise in the postoperative period. These complications are divided into Immediate complications and Late complications. Immediate complications include pain, fever, paralytic ileus, abscess (superficial or deep), wound infection/ dehiscence, enterocutaneous fistula. Late complications include adhesive intestinal obstruction and incisional hernia. ${ }^{[3,4]}$

The present study was a prospective study conducted to determine the incidence of 
Annals of International Medical and Dental Research

E-ISSN: 2395-2822 | P-ISSN: 2395-2814

Vol-8, Issue-1 | January-February 2022

DOI: $10.53339 /$ aimdr.2022.8.1.15

Page no- 106-116 | Section- Research Article (Surgery)

gastrointestinal perforation in the various age groups, sex, rural/urban, socio-economic status. We also assessed the various causes, sites of gastrointestinal perforations and different procedures being done to treat gastrointestinal perforation. $[5,6]$

\section{MATERIAL AND METHODS}

This study was conducted after approval from institutional ethical committee 100 cases presenting with perforation peritonitis in department of Surgery, Rajindra Hospital/ Govt. Medical College, Patiala were considered for the study after the informed consent. Patients underwent necessary investigations such as Blood counts, biochemical analysis and urine analysis. X-ray Abdomen and chest / USG Abdomen/Pelvis CT-Abdomen (as and when required). All diagnosed patients were subjected to surgery. In all cases, operative findings and postoperative course were followed up for three months. Final outcome was evaluated on the basis of clinical, operative and radiological findings.

In pre-pyloric and duodenal perforation, GRAHAM'S PATCH REPAIR carried out. In Ileal and Jejunal perforations, primary closure or exteriorization done depending upon the condition of the gut and duration of the symptoms. The patient outcome was assessed by duration of hospital stay, wound infection, wound dehiscence, leakage/entero-cutaneous fistula, intra-abdominal collection/abscess, ileostomy related complications and reoperation. Wound infection was graded as per SSI grading. The complications were managed as per standard guidelines with operative and non-operative means. Tabulation of cases was done. Data obtained was compiled and analysed by using SPSS statistics software 22 version.

\section{RESULTS}

Most common age group for perforation was $21-40$ years (50\%) followed by $41-60$ (33\%) years in present study. Mean age of the patients is $37.91+13.15$ years with male predominance $(78 \%)$ in our study. $4 \%$ of the patients were of upper socio-economic status while $32 \%$ of the patients were of middle and $64 \%$ of the patients were of lower socioeconomic status.

Abdominal pain was seen in $100 \%$ of the patients while abdominal distension was present in $69 \%$ of the patients. Nausea/Vomiting was seen in $61 \%$ of the patients while Fever and Constipation was seen in $53 \%$ and $86 \%$ of the patients respectively. Diarrhoea was seen in 3\% of the patients. Tenderness, guarding \& rigidity, distension, obliteration of liver dullness and evidence of free fluid were present in $100 \%$ of the patients. Bowel sounds were not detected in all the patients. Most common perforations were Duodena (37\%), Ileal (25\%), Gastric (25\%) followed by Appendicular (9\%), Jejunal (4\%) and Colonic perforation (2\%). The most common etiology of gastrointestinal perforations was Peptic ulcer followed by Typhoid, Appendicitis, Tuberculosis, Trauma, Malignancy and non-specific infection.

In Gastric perforations, Peptic ulcer was the most common cause of perforation followed by Trauma. In Ileal perforations, Typhoid was the most common cause of perforation followed by Tuberculosis and non-specific infection. In Appendicular perforations, most common 
Annals of International Medical and Dental Research

E-ISSN: 2395-2822 | P-ISSN: 2395-2814

Vol-8, Issue-1 | January-February 2022

DOI: $10.53339 /$ aimdr.2022.8.1.15

Page no- 106-116 | Section- Research Article (Surgery)

cause was Appendicitis. In Jejunal perforations, most common cause was Trauma. In Colonic perforations, most common cause was Malignancy. [Table 4] showed the incidence of surgical treatment given according to the site of perforation. The Outcome of patients with gastrointestinal perforation. Death occurred in 5\% (N=5) of the patients. While $95 \% \quad(\mathrm{~N}=95)$ of the patients showed survival. [Figure 5].

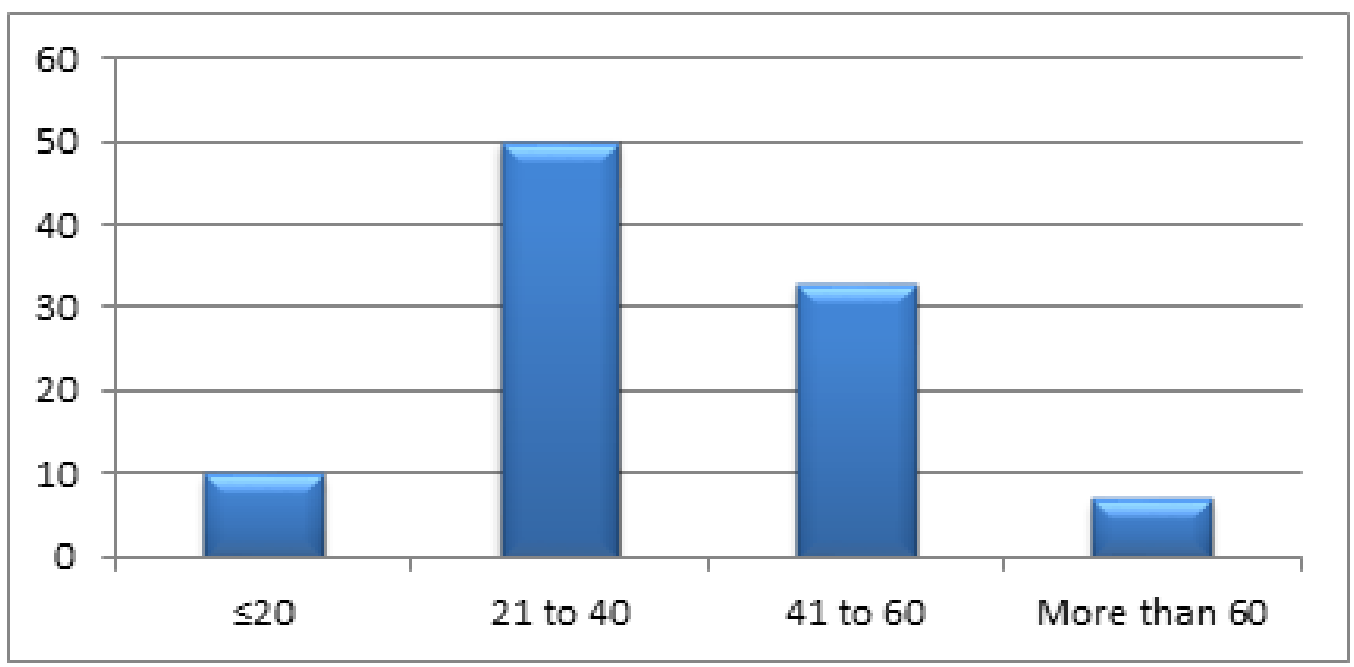

Figure 1: Incidence of gastrointestinal perforations according to different age groups

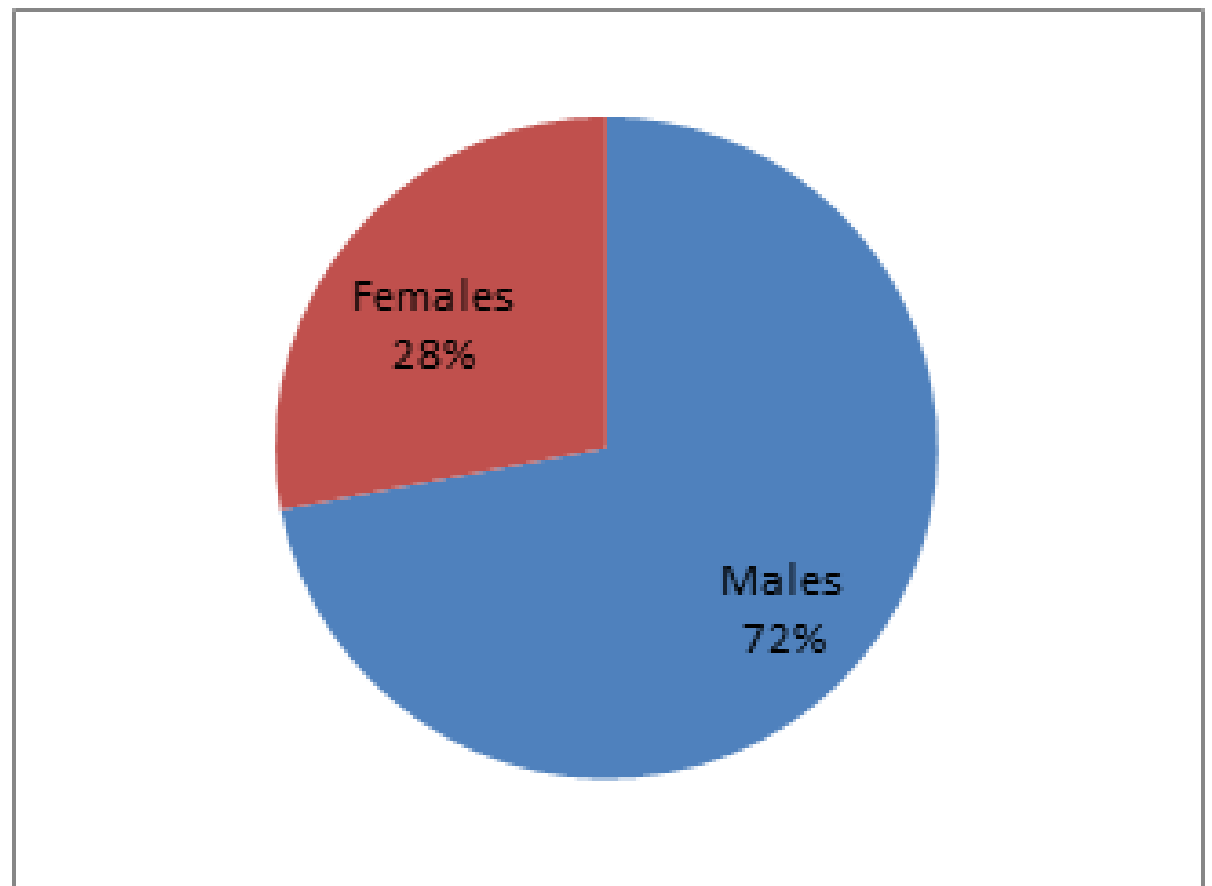

Figure 2: Incidence of gastrointestinal perforations according to gender. 
Annals of International Medical and Dental Research

E-ISSN: 2395-2822 | P-ISSN: 2395-2814

Vol-8, Issue-1 | January-February 2022

DOI: 10.53339/aimdr.2022.8.1.15

Page no- 106-116 | Section- Research Article (Surgery)

Table 1: Shows the incidence of various associated symptoms in gastrointestinal perforations.

\begin{tabular}{|l|l|}
\hline Signs & Number of patients \\
\hline Abdominal pain & 100 \\
\hline Abdominal distension & 69 \\
\hline Nausea/ vomiting & 61 \\
\hline Fever & 53 \\
\hline Constipation & 86 \\
\hline Diarrhoea & 3 \\
\hline
\end{tabular}

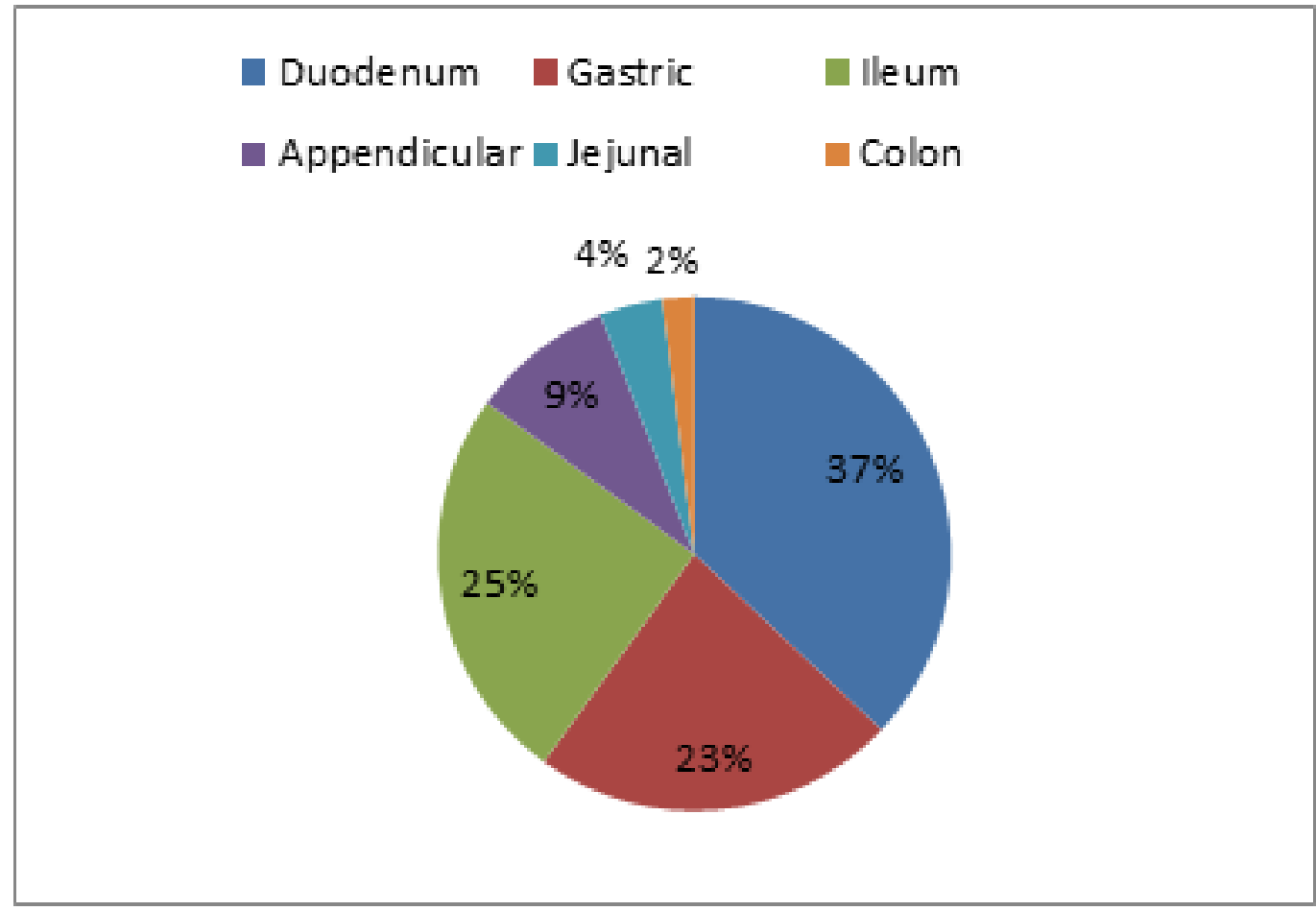

Figure 3: Distribution of patients according to the site of perforation

Table 2: Etiologic profile of gastrointestinal perforations

\begin{tabular}{|l|l|}
\hline Etiologic profile & Number of patients \\
\hline Peptic ulcer & 57 \\
\hline Trauma & 7 \\
\hline Typhoid & 15 \\
\hline Tuberculosis & 8 \\
\hline Appendicitis & 9 \\
\hline Malignancy & 2 \\
\hline Non-specific infection & 2 \\
\hline Total & 100 \\
\hline
\end{tabular}


Annals of International Medical and Dental Research E-ISSN: 2395-2822 | P-ISSN: 2395-2814

Vol-8, Issue-1 | January-February 2022

DOI: $10.53339 /$ aimdr.2022.8.1.15

Page no- 106-116 | Section- Research Article (Surgery)

Table 3: Correlation of site of gastrointestinal perforations according to the etiologic profile.

\begin{tabular}{|l|l|l|l|l|l|l|l|l|l|l|l|l|l|l|l|}
\hline \multirow{2}{*}{$\begin{array}{l}\text { Etiologic } \\
\text { profile }\end{array}$} & Duodenum & Gastric & \multicolumn{2}{l|}{ Ileum } & \multicolumn{2}{|l|}{ Appendicular } & \multicolumn{2}{l|}{ Jejunal } & \multicolumn{2}{|l|}{ Colon } & \multicolumn{2}{l|}{ Total } \\
\cline { 2 - 17 } & $\mathbf{N}$ & $\mathbf{\%}$ & $\mathbf{N}$ & $\mathbf{\%}$ & $\mathbf{N}$ & $\mathbf{\%}$ & $\mathbf{N}$ & $\mathbf{\%}$ & $\mathbf{N}$ & $\mathbf{\%}$ & $\mathbf{N}$ & $\mathbf{\%}$ & $\mathbf{N}$ & $\mathbf{\%}$ \\
\hline Peptic ulcer & 36 & $97.29 \%$ & 21 & $91.30 \%$ & 0 & $0 \%$ & 0 & $0 \%$ & 0 & $0 \%$ & 0 & $0 \%$ & 57 & $57 \%$ \\
\hline Trauma & 1 & $2.71 \%$ & 2 & $8.7 \%$ & 0 & $0 \%$ & 0 & $0 \%$ & 4 & $100 \%$ & 0 & $0 \%$ & 7 & $7 \%$ \\
\hline Typhoid & 0 & $0 \%$ & 0 & $0 \%$ & 15 & $60 \%$ & 0 & $0 \%$ & 0 & $0 \%$ & 0 & $0 \%$ & 15 & $15 \%$ \\
\hline Tuberculosis & 0 & $0 \%$ & 0 & $0 \%$ & 8 & $32 \%$ & 0 & $0 \%$ & 0 & $0 \%$ & 0 & $0 \%$ & 8 & $8 \%$ \\
\hline Appendicitis & 0 & $0 \%$ & 0 & $0 \%$ & 0 & $0 \%$ & 9 & $100 \%$ & 0 & $0 \%$ & 0 & $0 \%$ & 9 & $9 \%$ \\
\hline Malignancy & 0 & $0 \%$ & 0 & $0 \%$ & 0 & $0 \%$ & 0 & $0 \%$ & 0 & $0 \%$ & 2 & $100 \%$ & 2 & $2 \%$ \\
\hline $\begin{array}{l}\text { Non-specific } \\
\text { infection }\end{array}$ & 0 & $0 \%$ & 0 & $0 \%$ & 2 & $8 \%$ & 0 & $0 \%$ & 0 & $0 \%$ & 0 & $0 \%$ & 2 & $2 \%$ \\
\hline Total & 37 & $100 \%$ & 23 & $100 \%$ & 25 & $100 \%$ & 9 & $100 \%$ & 4 & $100 \%$ & 2 & $100 \%$ & 100 & $100 \%$ \\
\hline
\end{tabular}

Table 4: incidence of surgical treatment given according to the site of perforation

\begin{tabular}{|l|l|l|l|}
\hline Site & Operative Procedure & Number of patients & \%age \\
\hline \multirow{3}{*}{ Duodenum $(\mathrm{n}=37)$} & PC with OP & 33 & $89.18 \%$ \\
\cline { 2 - 4 } & B/L flank drain & 4 & $10.81 \%$ \\
\hline \multirow{3}{*}{ Gastric $(\mathrm{n}=23)$} & PC with OP & 20 & $86.95 \%$ \\
\cline { 2 - 4 } & Closure in single layer & 3 & $13.04 \%$ \\
\hline \multirow{2}{*}{ Jejunum $(\mathrm{n}=25)$} & Closure in single layer & 10 & $40 \%$ \\
\cline { 2 - 4 } & PC with OP & 13 & $52 \%$ \\
\cline { 2 - 4 } & Resection \& anastomosis & 2 & $8 \%$ \\
\hline Appendix $(\mathrm{n}=9)$ & Closure in single layer & 3 & $75 \%$ \\
\cline { 2 - 4 } & Resection \& anastomosis & 1 & $25 \%$ \\
\hline Colon $(\mathrm{n}=2)$ & Appendectomy & 9 & $100 \%$ \\
\cline { 2 - 4 } & Primary Closure & 1 & $50 \%$ \\
\cline { 2 - 4 } & Colostomy & 1 & $50 \%$ \\
\hline
\end{tabular}

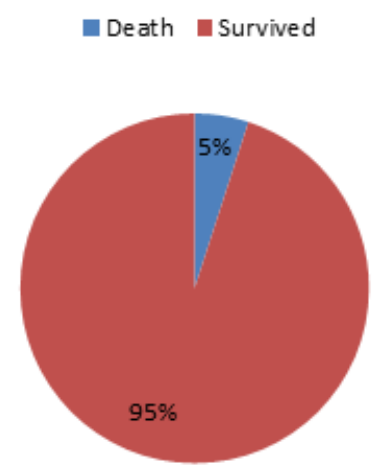

Figure 4: Outcome of patients with gastrointestinal perforation 
Annals of International Medical and Dental Research

E-ISSN: 2395-2822 | P-ISSN: 2395-2814

Vol-8, Issue-1 | January-February 2022

DOI: $10.53339 /$ aimdr.2022.8.1.15

Page no- 106-116 | Section- Research Article (Surgery)

\section{DISCUSSION}

Despite progress in emergency medicine, gastrointestinal tract perforation remains a condition associated with considerable mortality, ranging from 30 to $50 \%$. Clinical presentation varies; oesophageal perforations can present with non-specific symptoms such as acute chest pain, odynophagia and vomiting; gastro-duodenal perforations typically present with acute abdominal pain, whereas colonic perforations tend to follow a slower progression course, presenting with secondary bacterial peritonitis or localised abscess formation. A subset of patients exhibits delayed symptoms, abscess formation that mimics an abdominal mass, or with sepsis.[7]

The most common age group for perforations was 21-40 years followed by 41-60 years with Mean age of $37.91+13.15$ years in our study. The results were in concordance with the result obtained by previous authors who also reported similar findings. (Singla $S$ et al Ersumo $\mathrm{T}$ et al and Utaal $\mathrm{M}$ et al). [6,7] Present study showed male predominance, similar results were reported by Utaal $M$ et al and Ersumo T et al.66,7] The male preponderance can be explained by excessive intake of alcohol, smoking, tobacco chewing which is more common in males than females. Also the incidence of acid peptic diseases is more in males as compared to the females.

In the present study Abdominal pain (100\%) was most common symptom followed by abdominal distension (69\%), Nausea/
Vomiting (61\%) Fever(53\%), Constipation(86\%) and Diarrhoea $(3 \%)$ of the patients. Tenderness, guarding \& rigidity, distension, obliteration of liver dullness and evidence of free fluid were present in $100 \%$ of the patients. Bowel sounds were not detected in all the patients.

In a study conducted by Gupta et al, authors reported that Pain, Vomiting, Distension and Fever presented in $100 \%, 80 \%, 66 \%$ and $20 \%$ respectively. ${ }^{[8]}$ Shah $\mathrm{PH}$, Panchal $\mathrm{HA}$, in their study reported presence of Abdominal pain, Vomiting, Distension and Nausea in 100\%, $72 \%, 22 \%$ and $10 \%$ of the patients with Peptic ulcer perforations. [9] In another study conducted by Shah KD et al, Pain, Vomiting, Distension of abdomen, Fever and Constipation were seen in 100\%, 76\%, 72\%, $56 \%$ and $64 \%$ of the patients respectively.[10] Chalya PL et al, in their study on patients with Peptic ulcer perforation, reported that the commonest presenting symptoms were sudden onset of Severe epigastric pain in 82 (97.6\%), Abdominal distension in $64(76.2 \%)$ and Vomiting in 31 (36.9\%) patients. [11] Bhamre S et al, in their study on patients with Tuberculosis perforation, reported that Fever, Pain abdomen, Vomiting, Abdominal distension, Constipation and Diarrhoea were seen in 100\%, $100 \%, 66.67 \%, 62.2 \%, 11.1 \%$ and $4.44 \%$ of the patients respectively. ${ }^{[12]}$ In a study conducted by Singla et al,[]ㅡ Acute abdominal pain was a symptom present in all the 100 cases. Other symptoms were Vomiting (64\%), Abdominal distension (38\%) and Fever (22\%). 
Annals of International Medical and Dental Research

E-ISSN: 2395-2822 | P-ISSN: 2395-2814

Vol-8, Issue-1 | January-February 2022

DOI: $10.53339 /$ aimdr.2022.8.1.15

Page no- 106-116 | Section- Research Article (Surgery)

Table 5: Distribution of patients according to the site of perforation

\begin{tabular}{|l|l|l|l|l|}
\hline Site & Present study $\mathbf{( \% )}$ & $\begin{array}{l}\text { Shah KD et al, } 10] \\
(\mathbf{0})\end{array}$ & Utaal et al,[7] (\%) & $\begin{array}{l}\text { Singla S et al,[5] } \\
(\mathbf{\%})\end{array}$ \\
\hline Duodenum & 37 & 60 & 20 & $43 \%$ \\
\hline Gastric & 23 & 8 & 27.5 & \\
\hline Ileum & 25 & 12 & 35 & $30 \%$ \\
\hline Appendicular & 9 & 14 & 10 & $10 \%$ \\
\hline Jejunal & 4 & 2 & 5 & $5 \%$ \\
\hline Colon & 2 & 2 & 2.5 & $7 \%$ \\
\hline $\begin{array}{l}\text { Meckel's } \\
\text { diverticulum }\end{array}$ & 0 & 2 & 0 & $6 \%$ \\
\hline Rectal & $0 \%$ & & $0 \%$ & $5 \%$ \\
\hline
\end{tabular}

In Gastric perforations, Peptic ulcer was the most common cause of perforation followed by Trauma. In Ileal perforations, Typhoid was the most common cause of perforation followed by Tuberculosis and non-specific infection. In Appendicular perforations, most common cause was Appendicitis. In Jejunal perforations, most common cause was Trauma. In Colonic perforations, most common cause was Malignancy. Our results were in concordance with the result obtained by Singla $S$ et al and Utaal MS et al who also reported Peptic ulcer was the most common cause for gastrointestinal perforations in their respective studies. ${ }^{[5,7]}$

The results of our study are in congruence with the studies Gupta et al and Vagholkar.[1,13] In their studies, Peptic perforation was the most common etiology followed by Typhoid perforations. Khanna et al however, showed Enteric fever as the most common cause (108 out of 204 cases). High incidence of peptic perforation was due to smoking and drinking habits of local population. [14]

In present study, in Duodenal and gastric perforations, Peptic ulcer was the most common etiology followed by Trauma. In Ileal perforations, Typhoid was the most common cause of perforation followed by Tuberculosis and non-specific infection. In Appendicular perforations, most common cause was Appendicitis. In Jejunal perforations, most common cause was Trauma. In Colonic perforations, most common cause was malignancy.

Shah PH, Panchal HA, conducted a study on acute peptic gastrointestinal perforations and found Duodenal involvement in 83.67\% $(\mathrm{N}=41 / 50)$ and Gastric involvement occurred in $16.33 \%(\mathrm{~N}=9 / 50)$ of the patients with Peptic ulcer perforations. [9]

Sule AZ, conducted a study on gastrointestinal perforations following blunt trauma abdomen and found that Ileum was involved in $34.78 \%$ 
Annals of International Medical and Dental Research

E-ISSN: 2395-2822 | P-ISSN: 2395-2814

Vol-8, Issue-1 | January-February 2022

DOI: $10.53339 /$ aimdr.2022.8.1.15

Page no- 106-116 | Section- Research Article (Surgery)

$(\mathrm{N}=8 / 23)$ of cases, Gastric in $8.69 \%(\mathrm{~N}=2 / 23)$ cases, Jejunal in 39.13\% ( $\mathrm{N}=9 / 23)$ cases, Colon in $8.69 \%(\mathrm{~N}=2 / 23)$ cases, Jejunal/Ileal in $8.69 \%$ $(\mathrm{N}=2 / 23)$ cases of traumatic perforation. Ciftci $\mathrm{AO}$ et al, in their study on patients with traumatic perforations found Gastric involvement occurred in $11.42 \% \quad(\mathrm{~N}=4 / 35)$ cases, Duodenalin 5.71\% ( $\mathrm{N}=2 / 35)$ cases, Ileum in $34.28 \%(\mathrm{~N}=12 / 35)$ cases, Jejunal in $31.42 \%$ $(\mathrm{N}=11 / 35)$, Colon in $5.71 \% \quad(\mathrm{~N}=2 / 35)$, Jejunal/Ileal in $8.57 \%(\mathrm{~N}=3 / 35)$ and Ileum and colon in $2.85 \%(\mathrm{~N}=1 / 35)$ cases of traumatic perforations. $[15,16]$

In patients with Duodenal perforations, PC with OP is done in $89.18 \%$ while $\mathrm{B} / \mathrm{L}$ flank drain is done in $10.81 \%$ patients. In Gastric perforations, PC with OP is done in $86.95 \%$ patients while closure in single layer is done in $13.04 \%$ patients. In patients with Ileal perforations, closure in single layer is done in $40 \%$ patients, PC with OP is done in 52\% patients and resection \& anastomosis is done in $8 \%$ patients. In patients with Jejunum perforations, closure in single layer is done in $75 \%$ patients while resection \& anastomosis is done in $25 \%$ patient. In patients with Appendicular perforations, appendectomy is done in $100 \%$ patients. In patients with Colon perforations, primary closure is done in 50\% patient and colostomy is done in $50 \%$ patient.

In a study conducted by Mukhopadhyay M, patients with traumatic perforations, treatment consisted of simple closure of the perforation, resection \& anastomosis and repair followed by protective colostomy for colonic perforations.[17]
In another study, Ciftci $\mathrm{AO}$, reported that Gastric and Duodenal involvement were treated with simple closure while Ileum involvement were treated with simple closure and resection \& anastomosis.[16]

Singla et al, in their study, reported that patients with traumatic perforations were managed with Primary repair (3 patients), resection \& anastomosis (1 patient) and ileostomy/colostomy (3 patients).[5]

In another study conducted by Arslan et al, the most affected organ was the Ileum, which was detected in 37 (39\%) patients. Primary repair was performed on 71 (74\%) patients. Resection was performed on 22 (23\%) patients while 3 (3 $\%$ ) patients underwent an ostomy.[18]

Bhamre et al, in their study on patients with Tubercular perforations reported that closure was done in $73.3 \%$ of the cases while resection $\&$ anastomosis was done in $22.2 \%$ of the cases. In another study by Chalya et al, simple closure of the perforations was the most commonly done procedure accounting for $78.8 \%$ of cases with tubercular perforation and this was generally done in two layers after excising the edges.[11] Shah PH et al, in their study on patients with Peptic ulcer perforation, simple closure + omentopexywas done in $80 \%$ of the patients while drainage was done in $4 \%$.[2] Singla et al, in their study on patients with Appendicular perforation reported that all the patients were treated with appendectomy.[5] 
Annals of International Medical and Dental Research

E-ISSN: 2395-2822 | P-ISSN: 2395-2814

Vol-8, Issue-1 | January-February 2022

DOI: $10.53339 /$ aimdr.2022.8.1.15

Page no- 106-116 | Section- Research Article (Surgery)

Table 6: shows Mortality outcome of gastrointestinal perforation of various studies

\begin{tabular}{|l|l|}
\hline Various studies & Mortality outcome \\
\hline Utaal et al,[] & $12.5 \%$ \\
\hline Noguiera et al,[19] & $10 \%$ \\
\hline Ciftci AO et al,[16] & $5.7 \%$ \\
\hline Arslan S et al,[18] & $5 \%$ \\
\hline Shah PH et al,[]ㅡ & $2.04 \%$ \\
\hline Chalya PL et al,[11] & $10.7 \%$ \\
\hline Nuhu A et al,[20] Nasio NA et al,[21] & $2-25 \%$ \\
\hline Bhamre et al,[]] & $6.67 \%$ \\
\hline Singla et al,[5] & $5 \%$ \\
\hline Present study & $5 \%$ \\
\hline
\end{tabular}

\section{CONCLUSIONS}

The incidence of gastrointestinal perforations was common in 21-40 years age group followed by 41-60 years age group with male preponderance in our study. The most common site of perforations was Gastroduodenal followed by Ileal perforations and the most common cause for these perforations

\section{REFERENCES}

1. Coppolino F, Gatta G, Di Grezia G, et al. Gastrointestinal perforation: ultrasonographic diagnosis. Crit Ultrasound J. 2013;5 Suppl 1(Suppl 1):S4. doi:10.1186/2036-7902-5-S1-S4

2. Svanes C, Søreide JA, Skarstein A, et al. Smoking and ulcer perforation. Gut. 1997;41(2):177-180. doi:10.1136/gut.41.2.177

3. Yadav D, Garg PK. Spectrum of perforation peritonitis in delhi: 77 cases experience. Indian J Surg. 2013;75(2):133-137. doi:10.1007/s12262-0120609-2

4. Chouhan MK, Pande SK. Typhoid enteric perforation. Br J Surg. 1982;69(3):173-5. doi: 10.1002/bjs.1800690321.

5. Singla S, Verma S, Garg P, Verma A, Noori MT, Yadav A. Pattern and Etiology of Patients with was peptic ulcer followed by typhoid. The most common procedure done to treat gastrointestinal perforations was primary closure, resection and anastomosis, appendectomy and stoma formation. However, small sample size and short follow up period were the limitations of the present study.

Gastrointestinal Perforations: An Observational Prospective Study. Int J Contemp Med Res. 2019;6(4):D6-

D9.

http://dx.doi.org/10.21276/ijcmr.2019.6.4.44

6. Ersumo T, W/Meskel Y, Kotisso B. Perforated peptic ulcer in Tikur Anbessa Hospital: a review of 74 cases. Ethiop Med J. 2005;43(1):9-13.

7. Utaal MS, Bali S, Batra P, Garg N. Clinical profile in cases of intestinal perforation. Int Surg J. 2017;4:1002-8. https://dx.doi.org/10.18203/23492902.isj20170851

8. Gupta S, Kaushik R, Sharma R, Attri A. The management of large perforations of duodenal ulcers. BMC Surg. 2005;5:15. doi:10.1186/1471-24825-15

9. Shah PH, Panchal HA. Acute peptic perforation: clinical profile and our experience with operative outcome. Int Surg J. 2016;3:2227-32. 
Annals of International Medical and Dental Research

E-ISSN: 2395-2822 | P-ISSN: 2395-2814

Vol-8, Issue-1 | January-February 2022

DOI: $10.53339 /$ aimdr.2022.8.1.15

Page no- 106-116 | Section- Research Article (Surgery)

10. Domínguez-Vega G, Pera M, Ramón JM, Puig S, Membrilla E, Sancho J, et al. Tratamiento quirúrgico de la úlcera péptica perforada: comparación entre los abordajes laparoscópico y abierto [A comparison of laparoscopic versus open repair for the surgical treatment of perforated peptic ulcers]. Cir Esp. 2013;91(6):372-7. doi: 10.1016/j.ciresp.2012.10.016.

11. Chalya C. Typhoid intestinal perforations at a University teaching hospital in Northwestern Tanzania: A surgical experience of 104 cases in a resource-limited setting. World J Emerg Surg. 2012;7(4):1-11. https://doi.org/10.1186/1749-79227-4

12. Bhamre S, Chandak SS. A Clinical Profile of Typhoid Perforation of Bowel in a Tertiary Care Centre. MVP J Med Sci. 2016;3(2):83-91.

13. Yadav D, Garg PK. Spectrum of perforation peritonitis in delhi: 77 cases experience. Indian J Surg. 2013;75(2):133-137. doi:10.1007/s12262-0120609-2

14. Khanna AK, Misra MK. Typhoid perforation of the gut. Postgrad Med J. 1984;60(706):523-5. doi: 10.1136/pgmj.60.706.523.

15. Sule AZ, Kidmas AT, Awani K, Uba F, Misauno M. Gastrointestinal perforation following blunt abdominal trauma. East Afr Med J. 2007;84(9):42933. doi: 10.4314/eamj.v84i9.9552.

16. Ciftci AO, Tanyel FC, Salman AB, Büyükpamukcu $\mathrm{N}$, Hiçsönmez A. Gastrointestinal tract perforation due to blunt abdominal trauma. Pediatr Surg Int. 1998;13(4):259-64. doi: 10.1007/s003830050311.

17. Mukhopadhyay $M$. Intestinal injury from blunt abdominal trauma: a study of 47 cases. Oman Med J. 2009;24(4):256-9. doi: 10.5001/omj.2009.52.

18. Arslan S, Okur MH, Arslan MS, Aydogdu B, Zeytun H, Basuguy E, et al. Management of gastrointestinal perforation from blunt and penetrating abdominal trauma in children: analysis of 96 patients. Pediatr Surg Int. 2016;32(11):10671073. doi: $10.1007 /$ s00383-016-3963-5.

19. Noguiera C, Silva AS, Santos JN, Silva AG, Ferreira J, Matos E, et al. Perforated peptic ulcer: main factors of morbidity and mortality. World J Surg. 2003;27(7):782-7. doi: 10.1007/s00268-003-6645-0.

20. Nuhu A, Madziga AG, Gali BM. Acute perforated duodenal ulcer in Maiduguri: experience with simple closure and Helicobacter pylori eradication. West Afr J Med. 2009;28(6):384-7. doi: 10.4314/wajm.v28i6.55032.

21. Nasio NA, Saidi H. Perforated peptic ulcer disease at Kenyatta National Hospital, Nairobi. East Central African J Surg. 2009;14(1):13-6.

Source of Support: Nil, Conflict of Interest: None declared 